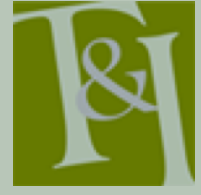

The International Journal for Translation \& Interpreting Research trans-int.org

\section{Explicitation across literary genres: evidence of a strategic device?}

\author{
Mehdi Vahedi Kia \\ Allameh Tabatabaei University, Iran \\ vahedikia@gmail.com \\ Helen Ouliaeinia \\ University of Isfahan, Iran \\ Sobh-e Sadegh Institute of Higher Education, Isfahan, Iran \\ helen_ouliaeinia@yahoo.com
}

DOI: 10.12807/ti.108202.2016.a06

\begin{abstract}
The present study is an attempt to investigate lexical explicitation in English translations of modern Persian literary works in different genres, namely prose, poetry, and drama. To this end, 8 novels and short stories, 6 dramas, and 13 Persian poems were randomly selected along with their English translations and were then analyzed based on the model of lexical explicitation in literary translation proposed by Vahedi Kia (2011). The results show that different lexical explicitations are typical of all literary genres except for extension of proper nouns and filling of elliptical structures, which did not show typicality in poetry. The results also indicated that narrowing is the most frequent of these explicitations in fiction and poetry, and addition of conjunctions the most common in drama translation. Interestingly, the findings suggest that at least in drama, the outwardly rather conscious tendency to undergo such a shift accounts for compensating for characterization and/or performability in translation, i.e. some of the characteristic features inherent in the genre in question.
\end{abstract}

Keywords: explicitation, literary genres, performability, shift-aversion, characterization

\section{Introduction}

One main object of Descriptive Translation Studies - thanks to Holmes' introduction of the 'translation map' in 1972 - has been the study of the language of translated texts as distinct from that of their originals in terms of textual manifestation. This gave an added impetus for putting forward the notion of translation tendencies or patterns in Translation Studies; yet a step further, translation universals and laws have been proposed in this respect (Baker, 1993 in Laviosa-Braithwaite, 1998; Toury, 1995). One of the most extensively studied of all these tendencies in the bulk of research conducted in the area to date is explicitation, which is defined by Hatim and Munday as "explanation in the TT that renders the sense or intention clearer than in the ST" (2004, p. 339). Some researchers in the field (e.g., Baker, 1993; Laviosa-Braithwaite, 1998) have 
proposed it as the prime candidate for a translation universal - a textual feature posited to be an "almost inevitable by-product of the process of translation, irrespective of the language pair involved" (Shuttleworth \& Cowie, 1997, p. 193). Since Baker's proposal of translation universals (Baker, 1993 in LaviosaBraithwaite, 1998), explicitation has been the object of many studies covering aspects such as the cognitive processes that translators perform, questions of translators' style, and textual analyses of the translated texts.

One area of interest in the latter case would be the study of literary texts in terms of these tendencies or alleged universals for the unique textual features they enjoy: literary texts "fulfil[1] an affective/aesthetic rather than transactional or informational function [....and] are characterized by 'poetic' language use (where language form is important in its own right [...]" among other textual features (Jones, 2009, p.152 (original emphasis and parentheses)). This implies that the very nature of literary language gives it its own niche, which thus introduces the dichotomy of 'literary vs. non-literary translation'. Be that as it may, within the literary domain, literary works in turn take on different textual manifestations in different literary genres: poetry exploits musical properties and a very condensed language as its most prominent features; literary prose - however liberated from certain textual poetical restraints - is still characterized for its phonetic and cohesive effects, thematic concentration, connotative and symbolic power, and structure and style (Newmark, 1988, 1993); drama is gestic and differs from the two other genres on account of its inherent duality of language and acoustic and visual expression (Piette, 2005). Message is taken to play a central role in literary works and is deemed inseparable from the text. In such texts, sound, grammatical structure, word order, and repetition contribute to the whole message and cannot be altered (Senn, cited in Newmark, 1993).

Given these features, literary texts are - at least in theoretical accounts assumed to be particularly shift-aversive due to their very delicate nature, and any over-/under-representativeness through their translation is frowned upon. Berman (2000 [1985]), for instance, finds expansion and qualitative impoverishment to be 'deforming strategies' when it comes to literary translation, regardless of the fact that such tendencies might arise out of subconscious cognitive processes.

Based on these theoretical grounds, the present study sets out to explore how explicitation-averse literary texts can be in practice. The study embraces two main objectives. Firstly, it attempts to shed light on the behaviour of lexical explicitation in different literary genres, as a part of the bottom-up approach in the search for translation universals in Persian-English translations and in literary translation - in particular, by observing and recording the extent to which different patterns of explicitation are resorted to in different genres. Secondly, we aim to provide possible explanations for the application of explicitation in literary texts, and in particular check whether this shift can serve as a strategic tool to attain the particular features of each genre.

As a point of departure, we assume that as a translation-inherent feature, explicitation is present in all translations irrespective of the language pair or the text type in question (see Blum-Kulka, 1968, below). That being the case, explicitation must manifest itself in literary translation and all its subcategories as a prevalent pattern while each subcategory inherently enjoys its own particular linguistic properties. We also assume that explicitation arises out of subconscious cognitive processes in translation (see Olahan, 2001, below), and translators resort to such a shift unconsciously when dealing with texts of any kind, be they literary or otherwise. Ultimately, the study addresses the following questions: 
1) To what extent do literary genres yield to lexical explicitation?

2) In case lexical explicitation manifests itself in literary translation, what is its behaviour across different genres?

3) What possible rationales lie behind employing explicitation in literary translation as a distinct niche of text production?

4) Can explicitation in literary translation be regarded a result of subconscious cognitive processes or of deliberate ones, and in the latter case, to what purpose?

Our yardstick for distinguishing instances of explicitation has been that of Farrell and Hoyle (1995, p. 1) which takes implicit information as that which accommodates the following features: (a) it is not stated in words; (b) it is necessary for the correct understanding of facts, emotions, or logic in a given discourse; (c) the original author intended the original audience to understand the discourse correctly. This is illustrated below in the example drawn from the data where the explicitation has been presented in bold italic. Our rough translation (RT) of the source text has also been given without explicating any part of the sentence except where it is symmetrical, i.e. required by the linguistic code to be grammatical.

يكى دكتر داريم كه قدرنى خدا جيزى سرش نميشود.

[...] we have a resident doctor who, by the grace of God, does not know a thing. (Bashiri, n.d.)

Yek doctor darim ke ghodratie Khoda chizi sarash nemishavad.

RT: We have a doctor who, by the grace of God, does not know anything.

The overall structure of the paper will be as follows: in section two, we will present the theoretical background and a brief review of the literature. Section three deals with data collection and methodology, and in section four, the results of the study will be presented to indicate the frequency of various lexical explicitations applied in each genre. Ultimately, the findings will be discussed with respect to the particular characteristics that each genre enjoys and along with other research to shed light on the possible grounds for resorting to such shifts.

\section{Explicitation: Background and Literature}

Many studies have taken explicitation as the object of their studies (e.g. chronologically, Séguinot 1988; Schjoldager, 1995; Øverås, 1998; Nikasa, 1999; Olahan \& Baker, 2000; Olahan, 2001; Dimitrova, 2005; Klaudy \& Károly, 2005; Pym, 2005; Gumul, 2006; Liashchenko, 2006; Gumul, 2007; Roozgar, 2007; Baumgarten et al., 2008; Kamenická, 2008; Saldanha, 2008; Vahedi Kia, 2009; Vahedi Kia, 2011; Korpal, 2012). We will present a brief overview of the theoretical foundations and literature of the descriptive studies conducted most relevant to this paper in the paragraphs that follow.

The concept of explicitation was first used by Vinay and Darbelnet in 1958 as "the process of introducing information into the target language which is present only implicitly in the source language, but which can be derived from the context or the situation" (1995 [1958], p. 342). Yet the first systematic study of explicitation came from Blum-Kulka (2000 [1986]) where, in her seminal Shifts of 
Cohesion and Coherence in Translation, she differentiated between two types of shift arising due to cohesiveness in the TT, namely shifts in textual meaning and shifts in explicitness, positing that with an increase in the former, the TTs prove more cohesive and hence more redundant. On the same basis, she formulated her 'explicitation hypothesis' which has served ever since as the departure point for most research taking explicitation into account:

The process of source text interpretation performed by the translator might lead to a TL text which is more redundant than the SL text. This redundancy can be expressed by a rise in the level of cohesive explicitness in the TL text. This argument may be stated as "the explicitation hypothesis", which postulates an observed cohesive explicitness from SL to TL texts, regardless of the increase traceable to differences between the two linguistic and textual systems involved. It follows that explicitation is viewed here as being inherent to the process of translation. (p. 300; original emphasis and italics)

Séguinot (1988) studied explicitation and institutional attitudes, and her findings confirmed presence of this tendency in translations in terms of improved topic-comment links and improved focus, and the addition of linking words. She held that explicitation of information, and explicitation of textual and logical links, are both by-products of institutional translation, although lexical explicitation depends on stylistic preferences of the TL and the institution in question. Similarly, Øverås (1998) investigated a corpus of novels, maintaining that the use of cohesive markers in translation is closely linked to explicitation. By the same token, Øverås accounted explicitation as a characteristic feature of the translation process.

One of the most widely quoted studies into explicitation comes from Olahan and Baker (2000), who investigated explicitation in two corpora - namely TEC (Translational English Corpus) and BNC (British National Corpus) - in the use of optional that after the reporting verbs say and tell, in order to provide evidence of the presence of subconscious explicitation in translations into English. The results indicated that the 'that-connective' is present in both corpora, but is more frequent in TEC than in BNC; conversely, the zero-connective is more frequent in BNC. In her later research on syntactic explicitation, Olahan (2001) concluded that the tendency of not omitting optional syntactic patterns in the translated texts may be subconscious, resulting from the nature of the translation process and the cognitive processes required thereby, rather than pertaining to deliberate decision making processes of which translators are aware.

In similar process-oriented studies, Dimitrova (2005) and Denver (2007) addressed translators at divergent levels of expertise in their Think Aloud Protocols (TAPs) project. Both studies recorded explicitation as a pattern applied by all the translators, professional and non-professional alike, and indicated that in the writing process all translators tended to add connectives to their translations. Furthermore, Denver held that in the decision-making phases of translation, professional translators made the strategic decision of explicitation in the writing phase while the others reconsidered cohesive marking in the revision phase.

In her search of the phenomenon in simultaneous translation and in a retrospective study, Gumul (2006) found explicitation to be not only a universal feature but also a strategic tool to overcome linguistic and socio-cultural differences. Interestingly, her subsequent study (2007) of two recorded English speeches translated into Polish by simultaneous and consecutive trainee interpreters revealed that marked diverse shift patterns of explicitation exist in 
simultaneous and conference interpreting particularly with a higher proportion of connectives added in the latter.

As already seen, most studies have so far set out to examine explicitation mainly in terms of cohesive markedness - i.e. the addition of connectives and cohesive elements. Moreover, most research conducted in this respect falls outside the boundaries of literary texts. The present study aims at tracing the behaviour of explicitation beyond mere cohesiveness in different literary genres, offering explanations as to whether such a phenomenon arises out of subconscious processes (as previously assumed with non-literary texts), and ultimately shedding light on possible grounds for resorting to such a shift.

\section{Data and Methodology}

The data used in this qualitative study of explicitation encompass a randomly selected sample of literary texts in different genres in Persian, along with their English translations. The parallel corpus consists of 13 Persian poems, 6 dramas, and 8 fictional works (short stories and novels), comprising 80,000 source-text words overall. It should be noted that the focus has been solely on contemporary Persian literary texts, bearing in mind that some literary (sub)genres (for example, the novel) have only recently been introduced to Persian. In some cases a given source text had multiple translations, allowing more than one translation to be analyzed here. Furthermore, regarding longer texts such as novels, only the first 100 sentences of the source texts have been analyzed along with their corresponding translations. A list of the Persian and English materials serving as the data for the study is presented in the appendix.

After data selection, each source text was compared with its English translation at the sentence level to identify and record the instances of lexical explicitation. The model used here to differentiate types of lexical explicitation is that of Vahedi Kia (2011), which primarily draws on Gumul's (2007) model itself in turn being basically adopted for the study of explicitation in spoken discourse i.e. interpreting. Nevertheless, the former is particularly developed to accommodate different patterns of lexical explicitation in 'literary translation'. The model applied involves the following:

1) Addition of Cultural Information

2) Narrowing

3) Addition of Conjunctions

4) Repetition

5) Reference Determination

6) Specification

7) Addition of Explanatory Vocabulary

8) Filling of Elliptical Constructions

9) Deduction

10) Extension of Proper Nouns

11) Disidiomatization 


\section{Data Analysis and Results}

In this section, an example of each kind of explicitation will be given from the data. The examples are provided with the explicitations being marked in bold italic. In addition, our rough translation (RT) for each of the examples has been given without explicating any part of the text (except for case where this shift occurs obligatorily) to help trace the explicitations in each example.

\section{Addition of Cultural Information:}

[...] ولي ميخو استم محلي را كه روز سيزده بهـدر او را آنجا ديده بودم، بيدا كنم.

[...] I wanted to find the place where I saw her on the $13^{\text {th }}$ day of Farvardin. (Bashiri, n.d.)

Vali mikhaastam mahalli raa ke ruze Sizdah-be-dar u raa aanja dideh budam, peida konam.

RT: But I wanted to find the place where I saw her on Sizdah-Be-Dar.

\section{Addition of Conjunctions:}

I'd box his ears. And he'd laugh. (Meisami, 1980, p. 336)

Mizadam tuye gushesh. Mikhandid.

RT: I would slap him. He would laugh.

\section{Filling of Elliptical Constructions:}

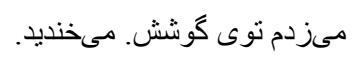
142)

Sad sharaf daarad... ghaachaagh ke nemikonam...

RT: It's more honorable than ... I am not smuggling ...

\section{Specification:}

نفر اول: مىرى و دستكيره را مىكيرى و مىكثى.

The First Person: You go into the door, hold the handle, and pull it. (Mehrjooya, p.

Nafare avval: Miri va dstgirreh ar migiri va mikeshi

RT: You go, and hold the handle, and pull it.

\section{Addition of Explanatory Vocabulary:}

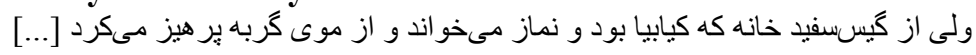

But she didn't like Kyabia, the elderly woman in the house. She prayed and, necessarily, avoided cat's hair. (Bashiri, n.d.)

Vali gis-sefide khaaneh ke kiabia bud va namaaz mikhaand va az muye gorbeh hazar mikard.

RT: But she avoided the old one in the house, the senior, who prayed and avoided cat's hair.

\section{Repetition:}

I can hear the garden breathing

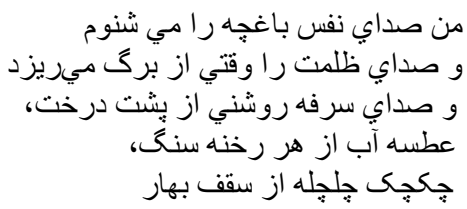

And the sound of darkness when dropping from a leaf

Translation \& Interpreting Vol 8 No 2 (2016) 
And the sound of light coughing from behind the tree

I can hear the sniffing of water through the crack of each rock

I can hear swallows dripping down from the spring's ceiling.

(Afshar, 2005, pp. 63-4)

Man sedaaye nafase baaghcheh ra mishanavam/va sedaaye zolmat raa vaghti az barg mirizad/va sedaaye sorfeye roshani az poshte derakht/atseye aab az har rekhneye sang/chek cheke chelcheleh as saghfe bahar

RT: I hear the breath of the garden

And the sound of darkness when it falls from the leaf

And the sound of the coughing of the light from behind the tree,

The sneeze of the water from behind each crack of the rock,

Dripping of swallows from the ceiling of spring.

\section{Reference Determination:}

PAYMAN Thanks God for his blessing, I submit. (Alaee, p. 17)

يِيمان: نعمت تو شكر. ما كه تسليميم.

Peymaan: ne'matet to shokr. Maa ke taslimim.

RT: PAYMAN: Thank you for your blessings. We submit.

\section{Narrowing:}

شاعرى ديدم هنگام خطاب به كل سوسن مىكفت شما

I saw a poet who addressed the lily of the valley as lady. (Afshar, 2005, p. 389)

Shaaeri didam hengame khataab beh gole susan migoft shoma.

RT: I saw a poet who addressed the lily as you.

\section{Extension of Proper Nouns:}

$$
\text { خاطره: مىخو اهم حرف بزنم، از فروغ بكويم [.... }
$$

Khatereh: I want to talk about Forough, my sister [...] (Boutorabi, Mirzai, and Torfeh, 2002, p. I-5)

Khaatereh: Mikhaham az Forough harf bezanam, az Forough beguyam.

RT: I want to talk; to speak about Forough.

\section{Disidiomatization:}

$$
\text { مقامى: نفرين كسى افتاده يشت سرم؟ }
$$

The First Person: Who did I hurt so that now they are destroying me in this way? (Ghandehari, p. 15)

Maghaami: Nefrine kasi oftadeh poshte saram?

RT: Has anyone cursed me?

\section{Deduction:}

$$
\text { اسم خدا را كجاها مىبرند، من بسته را نكرفتم. }
$$

Nothing's sacred, they'll drag the name of God into anything. I wouldn't take the package. (Wilks, 1997, p.138)

Esme Khodaa raa kojahaa mibarand, man basteh raa nagereftam.

RT: They use God's name everywhere. I didn't take the package.

The analysis of the corpus based on the above model revealed a total number of 364 instances of lexical explicitation. The findings of the study are summarized in Table 1, which presents the frequencies and absolute values of various lexical explicitations found in English translations of modern Persian literary works in the literary genres of fiction, drama and poetry. 
Table 1: Frequencies and absolute values of various types of lexical explicitations in different literary genres

\begin{tabular}{lrrr}
\hline Type of Lexical Explicitation & Fiction & Drama & Poetry \\
\hline Addition of cultural information & $5.48 \%$ & $5.14 \%$ & $3.12 \%$ \\
& 9 & 7 & 2 \\
\hline \multirow{2}{*}{ Addition of conjunctions } & $11.58 \%$ & $19.11 \%$ & $20.31 \%$ \\
& 19 & 26 & 13 \\
\hline \multirow{2}{*}{ Repetition } & $22.56 \%$ & $13.97 \%$ & $17.18 \%$ \\
Reference determination & 37 & 19 & 11 \\
\hline \multirow{2}{*}{ Narrowing } & $3.65 \%$ & $10.29 \%$ & $3.12 \%$ \\
& 6 & 14 & 2 \\
\hline \multirow{2}{*}{ Specification } & $30.48 \%$ & $14.70 \%$ & $29.68 \%$ \\
& 50 & 20 & 19 \\
\hline \multirow{2}{*}{ Addition of explanatory vocabulary } & $10.36 \%$ & $13.23 \%$ & $20.31 \%$ \\
& 17 & 18 & 13 \\
\hline \multirow{2}{*}{ Filling of elliptical constructions } & $6.09 \%$ & $4.41 \%$ & $3.12 \%$ \\
\hline \multirow{2}{*}{ Deduction } & 10 & 6 & 2 \\
\hline \multirow{2}{*}{ Extension of PNs } & $2.43 \%$ & $5.88 \%$ & - \\
\hline \multirow{2}{*}{ Disidiomatization } & 4 & 8 & $1.56 \%$ \\
\hline
\end{tabular}

The findings are also presented in the following figure, where the trends can be more easily compared.

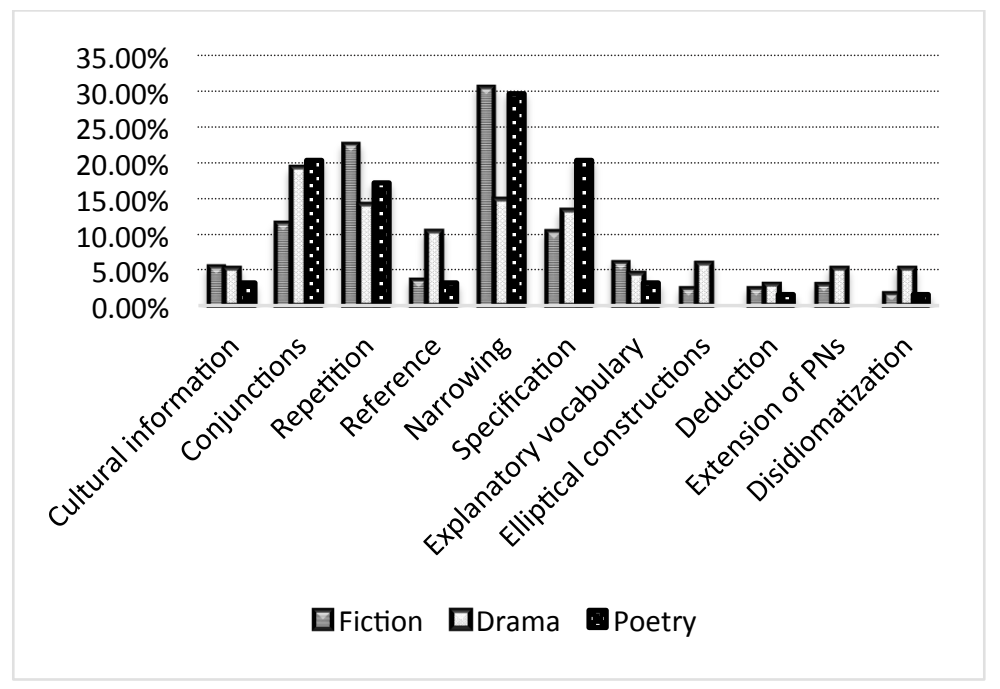

Figure 1. Explicitation by literary genre

First and foremost, the study indicates that explicitation proved prevalent in all literary genres, despite the particular textual characteristics that each genre displays. Moreover, the results reveal that explicitation manifests itself in a much wider pattern than just that of cohesive markedness in literary texts (i.e. through addition of linking words and cohesive elements): overall - except for filling of elliptical constructions and extension of PNs, which were not observed in poetry translation - other types of explicitation exhibited typicality in all the genres. The 
most frequent explicitation in fiction and poetry translation was narrowing (almost to the same extent in each case), and the most typical tendency for drama was the insertion of conjunctions. The use of repetition proved to be common in poetry and fiction also. Although the frequencies of applying additional cultural information and deduction in fiction, drama, and poetry did not differ much, other categories showed variation to different degrees.

\section{Discussion and Concluding Remarks}

The findings of the study promote the idea of explicitation as a universal feature in translated texts, given its manifestation in a niche of text production which is hypothetically held to be one of the most shift-aversive. The findings concur in many ways with those of previous research, particularly in terms of explicating cohesive elements. Given the 'addition of conjunctions' in the texts, which proved a common feature in all genres, the findings are in agreement with Blum-Kulka's explicitation hypothesis (2000 [1986]) suggesting that translated texts are more cohesive than non-translated ones, as well as with Dimitrova (2005) and Denver (2007) who claimed that translators tend to supply the missing connectives whose main function is to add to the cohesion of the text. This tendency was also reported by Séguinot (1988) and Øverås (1998), whose studies emphasized the specifying of grammatical ties in the translated texts, and by Zafarghandi (2006), who concluded that translators add elements at different levels in their attempt to produce a text which seems more natural and comprehensible to the end reader.

Furthermore, with regard to reference determination, the findings of this study are in line with Pym's (2005) assertion that copying the author's original references most likely results in ambiguities in the TL due to the TL's grammatical system (for instance, where the TL does not allow for distinguishing between the genders, as one example). According to Pym, disambiguation is a major rationale behind explicitation being used to minimize risks which might arise in the communication process. Furthermore, added cultural information, deduction, disidiomatization, and filling constructions that use ellipsis are clues to translators' attempts to be more cooperative with the reader (see Pym, 2005; Zafarghandi, 2006).

\section{Explicitation: a strategy in drama translation?}

Returning to our notion of explicitation as regards literary genres, it can be held that explicitation arises due to a variety of reasons such as disambiguation, being more cooperative, or making the TT more cohesive and more natural for the end readers. This is supported by many examples found in our data, particularly in the fiction genre, and has been discussed by previous research in the field. Interestingly, however, based on the instances found in drama translation in this study, explicitation served yet another function: it provides a means of emphasis, and offers a rhetorical device for the translator. One possible argument for resorting to such a shift could be that unlike interpretation and common translation practices, drama translation is subjected to a change of medium: "[d]ramatic translation stands between translation and interpretation: translation is written to written; interpretation is spoken to spoken; dramatic translation is written to written to spoken" (Newmark, 1998, p. 58). In other words, the language of drama stands in a functional relationship with the audience and the norms of spoken language (see Wellwarth, 1981; Levy cited in Aaltonen, 2000). 
By the same token, speakability and performability are given prime importance in drama translation. As Rappaport posits:

The playwright [translator] approaching a new version of a foreign-language play is bedevilled by many conflicts, not the least of which are maintaining a degree of linguistic loyalty to the original text and honouring the original playwright's intentions, whilst making the text accessible to the actors. $(2007$, p. 71$)$

There were instances in the data suggesting that drama translators had taken liberties in carrying out such linguistic alterations in order to make the texts more agreeable to the actors' spoken demands. This was primarily achieved by repetition and specification, as in the following example where explicitation is adopted to facilitate speakability/performability, and at the same time seeks to preserve the prosody of the spoken text. Thus, the repetitions of the word ending in $/ \mathrm{t} /$ as well as repetition of $/ \mathrm{d} /$ in the Persian text have been compensated for by the presence of $/ \delta /$ and $/ \Theta /$ by explicitation of the words 'trouble' and 'teaching' beginning with / $t$ / in English, which also develops a similar rhythm to that of the source sentence:

Thank you for the trouble of teaching math. (Alaee, p. 4)

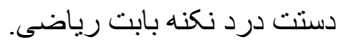

Dastet dard nakoneh baabate riaazi.

RT: Thank you for the math.

In the translation of another play analyzed in the study, 'From Windows Behind' by Akbar Radi, there was evidence of explicitation being used as an aid to characterization, where supplying longer stretches of dialogue for particular characters was used as a means to reveal their respective personalities. In the introduction of the translation of the play, the translator emphasizes how the character of the principal male actor in the play is meant to appear more silent: "[...] the silence of Bamdad injected in different parts of the play [...]" or "[... the playwright] has given the element of silence a musical application" (Shirmarz, 2007 , p. 6). An analysis of the play translation showed that there were much fewer explicitations employed for the two male characters than for the female ones, with males undergoing 4 and 5 explicitations respectively, compared to females whose speeches involved 12 explicitations each. The higher (presumably intentional) degree of explicitation applied by the translator to the female characters has served as a strategy to give clues about their personalities: their speeches having been made comparatively long and apparently redundant, the quietness of their male counterparts appears more evident.

The examples and evidence presented from our data in the preceding paragraphs, concerning the use of explicitation as a strategy to characterize and reveal the personality of the actors in drama, suggest that explicitation is a strategic technique adopted by translators to achieve literary quality in translation. Although Olahan (2001) posits that explicitation might arise due to subconscious cognitive processes, the findings imply that, at least with respect to literary texts, explicitation is seemingly applied rather deliberately to preserve the characteristic qualities inherent in particular genres. This finding is in line with Denver (2007) on the strategic use of this shift in his asymmetry hypothesis on literary journalism, particularly on the part of professional translators, and also with Gumul (2006) on the use of explicitation as a strategic device applied by interpreters. It should be noted that the degree of consciousness in application of 
explicitation can be best determined by examining the translator's cognitive processes through self-reporting techniques such as think aloud protocols (TAPs) or observation, and requires further research.

Be that as it may, generalizations on the use of this shift as a strategic means to assist the literary nature of literary texts cannot be made without further investigation and attention to the size, language pair, and translation direction of the data in the corpus. Furthermore, the low frequency of some of the explicitation categories (such as deduction and extension of proper nouns) potentially indicates a feature attributable to the brevity of literary language and the style of the translator, and thus the idea of shift-aversiveness in literary translation cannot be completely dismissed.

In the main, the results of the study indicate that, aside from the filling of ellipses and the extension of proper nouns in poetry, all investigated types of lexical explicitation were found in English translations of Persian literary texts across all genres, thereby demonstrating the occurrence of explicitation in patterns extending beyond that of mere cohesive markedness and further promoting explicitation as a candidate for a translation universal. Although literary texts are by their very nature considered to be the most delicate of all, and are correspondingly reported to undergo a minimum of shifts, those examined here nonetheless displayed a prevalent pattern of explicitation, which presumably is utilized purposely as a strategic device for assisting speakability, as well as characterization in drama.

\section{References}

Aaltonen, S. (2000). Time-sharing on stage: Drama translation in theatre and society. Great Britain: Cromwell Press Ltd.

Alaei, M. (n.d.). Sharp Splinter. Unpublished manuscript.

Bashiri, I. (2000). Three drops of blood. Retrieved Sep. 22, 2008, from www.angelfire.com/rnb/bashiri/Stories/3Drops.html

Bashiri, I. (n.d.). The blind owl. Retrieved Sep. 22, 2008, from http://www.angelfire.com/rnb/bashiri/BlindOwl/blindowl.html

Baumgarten, N., Meyer, B., \& Özçetin, D. (2008). Explicitness in translation and interpreting: A critical reveiw and some empirical evidence (of an elusive concept). Across Languages and Cultures, 2(9), 177-203.

Berman, A. (1985/2000). Translation and the trials of the foreign. In L. Venuti (Ed.), The Translation Studies Reader (L. Venuti, Trans., pp. 284-95). USA and Canada: Routledge.

Blum-Kulka, S. (1986/2000). Shifts of cohesion and coherence in translation. In L. Venuti (Ed.), The translation studies reader (pp. 298-313). USA and Canada: Routledge.

Denver, L. (2007). Translating the implicit: On the inferencing and transfer of semantic relations. In Y. Gambier, M. Shlesinger, \& R. Stolze (Eds.), Doubts and directions in translation studies: Selected contributions from the EST Congress, Lisbon 2004 (pp. 223-36). Amsterdam and Philadelphia: John Benjamins.

Dimitrova, B. (2005). Expertise and explicitation in the translation process. Amsterdam and Philadelphia: John Benjamins.

Farrell, T., \& Hoyle, R. (1995). Translating implicit information in the light of Saussurain, relevance, and cognitive theories. Notes on Translation, 9(1), 1-15.

Gumul, E. (2006). Explicitation in simultaneous interpreting: A strategy or a by-product of language mediation? Across Languages and Cultures, 7(2), 171-190.

Gumul, E. (2007). Explicitation in conference interpreting. In M. Thelen (Ed.), The 4th International Maastricht - LódźDuo Colloquium on "Translation and Meaning" (pp. 449-456). Maastricht: Zuyd University. 
Hatim, B., \& Munday, J. (2004). Translation: An advanced resource book. USA and Canada: Routledge.

Hilman, M. (1985). Lost in the crowd. Chicago: Three Continents Press.

Jones, F. (2009). Literary translation. In M. Baker \& G. Saldanha (Eds.), Routledge Encyclopedia of Translation Studies (2nd ed., pp. 152-8). USA and Canada: Routledge.

Kamenická, R. (2008). Explicitation profile and translator style. Retrieved Nov 24, 2008, from http://isg.urv.es/library/papers/KamenickaExplicitation.pdf

Klaudy, K., \& Károly, K. (2005). Implicitation in translation: Empirical evidence for operational asymmetry in translation. Across Languages and Cultures, 6(1), 13-28.

Korpal, P. (2012). Omission in simultaneous interpreting as a deliberate act. In A. Pym \& D. Orrego-Carmona (Eds.), Translation Research Projects 4 (pp. 103-112). Universitat Rovira i Virgili $\quad$ Retrieved from http://isg.urv.es/publicity/isg/publications/trp_4_2012/index.htm

Laviosa-Braithwaite, S. (1998). Universals of translation. In M. Baker (Ed.), The Routledge Encyclopedia of Translation Studies (pp. 288-91). USA and Canada: Routledge.

Lewis, F. (1997). The half-closed eye. In H. Moayyad (Ed.), Stories from Iran: A Chicago Anthology 1921-1991 (2nd ed., pp. 125-144). Washington D.C.: Mage Publishers.

Liashchenko, O. (2006). The explicitation of the implicit in English-Ukrainian-English translations. Retrieved Dec 24, 2008, from Translation Journal: http://accurapid.com/journal/44explicitation.htm

Mehrjooya, S. (2012). One room with two doors. Retrieved from Cloob: http://www.cloob.com/timeline/blog_459475_152918

Meisami, J. (1980). My china doll. In L. Hamalian \& J. Yohannan (Eds.), New writings from the Middle East (pp. 333-43). New York and Scarborough: Mentor Book.

Newmark, P. (1988). A textbook of translation. Oxford and New York: Prentice-Hall.

Newmark, P. (1993). Paragraphs on translation. Great Britain: Longdunn Press.

Newmark, P. (1998). More paragraphs on translation. Great Britain: The Cromwell Press.

Nikasa, H. (1999). Text linguistic models for the study of simultaneous interpreting. Retrieved from Stockholm University: http://www.geocities.com/ tolk/lic/licproj_w2wtoc.htm

Olahan, M., \& Baker, M. (2000). Reporting that in translated English: Evidence for subconscious processes of explicitation? Across Languages and Cultures, 1(2), 14158.

Olahan, M. (2001). Spelling out the optionals in translation: A corpus study. UCREL Technical Papers, 13, 423-432.

Øverås, L. (1998). In search of the third code: An investigation of norms in literary translation. Meta, 43, 557-570.

Piette, A. (2005). Translation and national cultures: A case study in theatrical translation. In E. Hung (Ed.), Translation and Cultural Change: Studies in History, Norms and Image-projection (pp. 111-8). Amsterdam and Philadelphia: John Benjamins.

Pym, A. (2005). Explaining explicitation. Retrieved Oct 5, 2007, from http://www.tinet.org/ apym/on-line/translation/explicitation_web.pdf

Rappaport, H. (2007). Chekhov in the Theatre: The role of the translator in new versions. In G. Anderman (Ed.), Voices in translation: Bridging cultural divides (pp. 6677). Great Britain: Cromwell Press Ltd.

Roozgar, M. (2007). Textual explicitation in two text-types: Expressive and informative. (Unpublished master's thesis). University of Isfahan, Isfahan, Iran.

Saberi, P. (2002). The voice alone: A play of love, death and beauty. (A. Boutorabi, P. Mirzai, \& M. A .Torfeh, Trans.). Tehran: Ghatreh.

Saldanha, G. (2008). Explicitation revisited: Bringing the reader into the picture. Transkom, $1(1), 20-35$.

Schjoldager, A. (1995). An exploratory study of translational norms in simultaneous interpreting: Methodological reflections. In P. Jansen (Ed.), Translation and the Manipulation of Discourse (pp. 227-243). Leuven: CETRA - The Leuven Research Center for Translation, Communication and Cultures.

Translation \& Interpreting Vol 8 No 2 (2016) 
Séguinot, C. (1988). Pragmatics and the explicitation hypothesis. Traduction, Terminologie, Rédaction, 1(2), 106-113.

Shuttleworth, M., \& Cowie, M. (1997). Dictionary of Translation Studies. Manchester: St. Jerome.

Toury, G. (1995). Descriptive translation studies and beyond. Amsterdam and Philadelphia: John Benjamins.

Vahedi Kia, M. (2009). Explicitation across literary genres in Persian-English translations. (Unpublished master's thesis). University of Isfahan, Iran.

Vahedi Kia, M. (2011). A model of lexical explicitation in literary translation. Translation studies, 8(32), 55-70.

Vinay, J., \& Darbelnet, J. (1958/1995). Comparative stylistics of French and English: A methodology for translation. Amsterdam and Philadelphia: John Benjamins.

Wellwarth, G. E. (1981). Special considerations in drama translation. In R. Gaddis (Ed.), Translation Spectrum: Essays in Theory and Practice (pp. 140-6). USA: State University of New York Press.

Wilks, J. (1997a). Mirza. In H. Moayyad (Ed.), Stories from Iran: A Chicago anthology 1921-1991 (2nd ed., pp. 61-85). Washington D. C.: Mage Publishers.

Wilks, J. (1997b). The little native boy. In H. Moayyad (Ed.), Stories from Iran: A Chicago Anthology 1921-1991 (2nd ed., pp. 171-202). Washington D. C.: Mage Publishers.

Zafarghandi, A. M. (2008). Relevance theory and explicitation strategy in translation. Retrieved Nov 28, 2008, from http://research.guilan.ac.ir/research/doc/a769.pdf 


\section{Appendix}

The following literary works served as the data for the study.

Fiction:

\begin{tabular}{|c|c|c|}
\hline Title in Persian/English & Writer & Translator \\
\hline & Simin Daneshvar & Frank Lewis \\
\hline & Sadegh Choobak & John R. Perry \\
\hline اخغسى در ميقات/Lost in the Crowd & Jalal Ale-Ahmad & Michel Hillman \\
\hline & Ahmad Mahmood & Judith Wilks \\
\hline & Sadegh Hedayat & Iraj Bashiri \\
\hline إمبرزا/Mirza & Bozorg Alavi & Judith Wilks \\
\hline /عروسك جينى من My China Doll/ & Hooshang Golshiri & Julie S. Meisami \\
\hline & Sadegh Hedayat & D. P. Castello \\
\hline إبوف كور/The Blind Owl & Sadegh Hedayat & Iraj Bashiri \\
\hline
\end{tabular}

\section{Drama:}

Title in Persian/English

Writer

Translator

از يشت شيشه ها:From Windows Behind

Akbar Radi

Reza Shirmarz

/ماهى سياه كوجولو

تركش Sharp Splinter

Samad Behrangi Manouchehr Harsini من از كجا عشق از كجا: بركرفته ازاشعار hoice Alone: A Play of Love, Death and Beauty

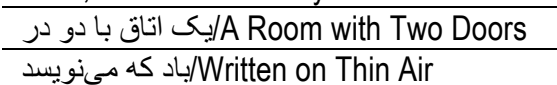

Atefeh Hosseini
Mahtab Alaee

باد كه مىنويسد/Written on Thin Air

Pari Saberi

Afsaneh Boutorabi, Pardis Mirzai, and Mark A. Torfeh

Poetry:

Title in Persian/English Mahmood Nazeri Sepideh Mehrjooya Arash Abbasi Shaghayegh Ghandehari

\begin{tabular}{|c|c|c|}
\hline Another birth & Forough Farokhzad & Karim Emami \\
\hline زمستان & Nima Yooshij & Mahvash Shahegh \\
\hline ازمستان/The Winter & Nima Yooshij & Iraj Bashiri \\
\hline & Sohrab Sepehri & Mehdi Afshari \\
\hline & Sohrab Sepehri & Karim Emami \\
\hline $\begin{array}{l}\text { ادر دل يك ده دور/Amidst a Distant } \\
\text { Country }\end{array}$ & Asadollah Shabani & Hosein Vahid Dastjerdi \\
\hline اجاق سرد & Nima Yooshij & Mahmoud Kianoosh \\
\hline /Dialogue & Mehdi Akhavan Sales & Naser Mohammadi \\
\hline ادعوت/The Call & Tahereh Saffaezadeh & $\begin{array}{l}\text { Mahmoud } \\
\text { Kermani }\end{array}$ \\
\hline & Siavash Kasraee & Ali Khazaeefar \\
\hline & Siavash Kasraee & Karim Emami \\
\hline $\begin{array}{l}\text { تصوير يك دريجه روشن/The Picture of a } \\
\text { Bright Window }\end{array}$ & Meimanant Mirsadeghi & Mahmoud Kianoosh \\
\hline /نall of the Start & Sohrab Sepehri & $\begin{array}{l}\text { Mohammad Ali Mokhtari } \\
\text { Ardakani }\end{array}$ \\
\hline كوجهـ/The Alley & Fereydoon Moshiri & Faranak Moshiri \\
\hline
\end{tabular}

